\title{
Tau: The Center of a Signaling Nexus in Alzheimer's Disease
}

\author{
Shahzad S. Khan and George S. Bloom* \\ Department of Biology, University of Virginia, Charlottesville, VA, USA
}

Tau is a microtubule-associated protein whose misfolding, hyper-phosphorylation, loss of normal function and toxic gain of function are linked to several neurodegenerative disorders, including Alzheimer's disease (AD). This review discusses the role of tau in amyloid- $\beta(A \beta)$ induced toxicity in $A D$. The consequences of tau dysfunction, starting from the axon and concluding at somadendritic compartments, will be highlighted.

Keywords: Alzheimer's disease (AD), Amyloid- $\beta$ oligomers (A $\beta O s)$, neurofibrillary tangles (NFTs), tau phosphorylation, synaptic dysfunction

\section{INTRODUCTION}

Alzheimer's disease $(\mathrm{AD})$ is a neurodegenerative disorder that causes an insidious decline in cognitive function. The greatest risk factor for $\mathrm{AD}$ is age and the chances of developing the disease increases two-fold every 5 years after age 65 . As the population continues to live longer, the toll that $\mathrm{AD}$ inflicts on healthcare costs for affected individuals will continue to rise. Thus, there is an urgent need to improve our understanding and therapeutic treatment of AD.

One of the barriers preventing the expeditious treatment of $\mathrm{AD}$ is our inability to detect at-risk individuals early enough for effective intervention. A diagnosis of $\mathrm{AD}$ can only be confirmed at autopsy following the detection of extracellular plaques containing $\mathrm{A} \beta$ peptides and intracellular neurofibrillary tangles composed of the neuron-enriched, microtubule-associated protein (MAP), tau. Since mutations in the amyloid precursor protein (APP) gene are linked to AD onset, and plaques often precede the formation of tau tangles, the amyloid cascade hypothesis, which states that $A \beta$ initiates hyper-phosphorylation and aggregation of tau, and overall $A D$ pathogenesis, was developed (Hardy and Higgins, 1992).

Although, it has been popular to focus primarily on $\mathrm{A} \beta$ in $\mathrm{AD}$, tau plays an equally important role in $\mathrm{AD}$ pathogenesis. For instance, individuals with substantial plaque loads but no evident tau pathology can lead healthy lives with no symptoms of cognitive decline (Sperling et al., 2009). Additionally, research has long supported the notion that tau is the major component of neurofibrillary tangles that positively and robustly correlate with AD severity Grundke-Iqbal et al., 1986; Nukina and Ihara, 1986; Kondo et al., 1988; Kosik et al., 1988; Braak and Braak, 1991; Götz et al., 2001; Lewis et al., 2001). Tau depletion also protects against $A \beta$-associated neuron death (Leroy et al., 2012; Nussbaum et al., 2012). Thus, it is generally accepted that tau dysfunction, manifested as hyper-phosphorylation and aggregation, are major proximal causes of neuron loss in $\mathrm{AD}$ (Bloom, 2014). This review emphasizes the role of tau as a central player in a pathogenic signaling nexus that underlies AD.

Received: 02 December 2015 Accepted: 25 January 2016 Published: 09 February 2016

Citation: Khan SS and Bloom GS (2016) Tau: The Center of a Signaling Nexus in Alzheimer's Disease.

Front. Neurosci. 10:31. doi: 10.3389/fnins.2016.00031

\section{BACKGROUND ON TAU}

Tau was originally identified as a predominant MAP present in mammalian brain (Weingarten et al., 1975). In the CNS, alternative splicing leads to the formation of six isoforms (Goedert et al., 1989a). Variation among the six isoforms lies in the number of exons expressed at the N-terminus 
$(0,1$, or 2$)$ and microtubule binding repeat domains near the C-terminal end of the protein (3 or 4). During early stages of mammalian development, the 3 repeat domain tau isoforms predominate and it is heavily phosphorylated (Goedert et al., 1989b). A proposed function for elevated tau phosphorlyation during development is that it contributes to synaptic plasticity (Frandemiche et al., 2014). As the brain ages, however, phosphorylation of tau decreases and the presence of 4 repeat to 3 repeat tau reaches an approximate 1:1 ratio (Goedert et al., 1989a,b; Himmler et al., 1989; Kosik et al., 1989; Goedert and Jakes, 1990; Hong et al., 1998).

\section{TAU FUNCTION}

The first antibody generated against tau helped determine that its expression is predominantly axonal (Binder et al., 1985). Subsequent experiments using the same antibody identified tau, and what would be later shown as hyper-phosphorylated tau, as the primary component of neurofibrillary tangles (GrundkeIqbal et al., 1986; Wood et al., 1986; Kondo et al., 1988; Kosik et al., 1988). The putative functions of tau include stimulation of tubulin polymerization, stabilization of microtubules (Witman et al., 1976), and a "speed bump" property whereby tau constrains the fast transport of organelles along microtubules (Stamer et al., 2002; Dixit et al., 2008). Tau is most concentrated in the distal portions of axons, where it helps regulate microtubule dynamics.

Methods designed to knockdown or knockout (KO) tau have identified additional roles for the protein in the CNS. Early work on tau depletion using antisense nucleotides suggested that tau is required for proper axon development and neuronal polarity (Caceres and Kosik, 1990). However, follow-up studies in vivo using tau $\mathrm{KO}$ mice were less convincing (Harada et al., 1994), and subsequent work in several tau KO strains reported no change in reproduction, physical appearance, or behavior (Dawson et al., 2001; Tucker et al., 2001). Nevertheless, during mouse postnatal development reduction of tau alters the migration and morphology of neurons, and also intracellular mitochondrial transport (Sapir et al., 2012). In Drosophila, global tau $\mathrm{KO}$ is developmentally lethal and targeted $\mathrm{KO}$ in neurons or the eye results in progressive neurodegeneration (Bolkan and Kretzschmar, 2014). However the lethality and neurotoxicity of tau $\mathrm{KO}$ in Drosophila might reflect a general paucity of microtubule-associated proteins in flies.

Much of the original work using tau $\mathrm{KO}$ mice extends to 6 months of age, leaving the long-term effects of tau depletion uncertain. Recent work has attempted to investigate the effects of prolonged tau ablation, with very inconsistent results. Work from one group demonstrated that aged tau KO mice (older than 6 months) develop iron accumulation, motor deficits, Parkinsonism with dementia, significant brain atrophy, and impaired Y-maze performance (Lei et al., 2012, 2014). Similarly, others have reported motor deficits in aged tau $\mathrm{KO}$ mice (Ma et al., 2014; Lopes et al., 2016), or decreased brain weight and mild hyperactivity in aged tau KO homozygotes (Li et al., 2014). Evidence of impaired learning, as determined by Barnes maze performance, was also recently reported (Regan et al., 2015).
However, other studies reported no difference in iron accumulation (Li et al., 2014), parkinsonian abnormalities in dopamine levels (Li et al., 2014), dopamine-related motor deficits (Morris et al., 2013; Ahmed et al., 2014; Li et al., 2014), or impaired Y-maze performance in aged tau $\mathrm{KO}$ mice ( $\mathrm{Li}$ et al., 2014). Furthermore, results demonstrated that Morris water maze performance is either improved or unaffected (Morris et al., 2013; Ahmed et al., 2014) which presents conflict to other data (Ma et al., 2014). Likewise, the literature reports inconsistent fear conditioning results in aged tau KOs. One study showed no difference in contextual fear conditioning (Li et al., 2014) while another reported impaired cue and contextual fear conditioning (Ahmed et al., 2014). The literature also reports contrasting data on long-term depression (LTD), with severe impairments in long-term potentiation and no effect on LTD shown by one group (Ahmed et al., 2014), and deficits in LTD demonstrated by others (Kimura et al., 2013; Regan et al., 2015).

These discrepancies might reflect strain-dependent phenotypic differences among the various tau KO mouse lines. Hence, as more studies are completed, and as methods become more standardized, we will be better able to resolve what consequences, or lack thereof, arise with prolonged tau ablation. Understanding the effects of prolonged tau ablation is not only important to elucidate tau function, but is also necessary to ascertain the best therapeutic strategy to employ when treating tau-related neurodegenerative disorders.

\section{TAU IMPAIRMENT AT THE AXON IN AD}

Among tau post-translational modifications its phosphorylation is the best characterized. There are 80 serine or threonine and 5 tyrosine sites at which tau can theoretically be phosphorylated. Once tau becomes aberrantly phosphorylated its functional capacity to stabilize microtubules is reduced, contributing to axon deficits in AD. Furthermore, axonal swellings, or varicosities, that are frequently observed during early-stage $\mathrm{AD}$, are hypothesized to reflect tau-associated defects in transporting cargo-containing vesicles (Krstic and Knuesel, 2012). Expression of tau phosphomimics lends supporting data to this theory by demonstrating that sustained tau (psuedo)phosphorylation impairs its axonal transport and degradation (Rodríguez-Martín et al., 2013). Other tau post-translational modifications, such as cis or trans isomerization, also affect the ability of tau to maintain microtubule assembly at axons (Nakamura et al., 2012).

In support of the amyloid cascade hypothesis, $A \beta$ oligomers (A $\beta O s)$ are reported to impair the ability for tau to stabilize microtubules. Our lab previously reported that pre-fibrillar $\mathrm{A} \beta$ stimulates tau-dependent disassembly of microtubules (King et al., 2006). It was likewise reported that $A \beta$ treatement promoted tau hyperphosphorlyation, microtubule-related deficits, and organelle dysfunction (Silva et al., 2011). Similarly, tau is implicated to trafficking deficits in cell surface receptors, particularly those that bind glutamate, following $\mathrm{A} \beta \mathrm{O}$ treatment (Li et al., 2009; Hoover et al., 2010). Thus, under atypical conditions $A \beta$ and tau interact to cause significant microtubule and transport dysfunction. 


\section{SOMADENDRITIC TAU}

A conspicuous property of tau in $\mathrm{AD}$ is its ectopic mislocalization to somatodendritic compartments (Götz et al., 1995; Hoover et al., 2010). It is hypothesized that an $A \beta$ and tau interaction causes the synaptotoxicity commonly observed in AD. For instance, double transgenic mice that overexpress the human forms of APP (containing the Swedish and London mutations, for example) and WT tau acquire significant dendritic spine loss with age (Chabrier et al., 2012, 2014). Mechanistically, $\mathrm{A} \beta$ exposure promotes complex formation between the nonreceptor tyrosine kinase, fyn, and PSD95, in a tau-dependent manner, to mediate aberrant activation of the NMDA receptor in dendritic spines (Ittner et al., 2010). Some synapse dysfunction following $A \beta$ exposure also requires formation of a complex containing fyn and the cellular prion protein, and fyndependent phosphorylation of tau (Larson et al., 2012). Tau phosphorylation by other kinases, such as AMP-activated kinase (AMPK) is further necessary for $\mathrm{A} \beta \mathrm{O}$ synaptotoxicity (MairetCoello et al., 2013). In addition to the requirement of tau for the $A \beta O$-initiated activation of the NMDA receptor, recent work has shown that $\mathrm{A} \beta \mathrm{O}$ s elicit phospho-tau infiltration to dendrites and AMPA receptor dysfunction (Miller et al., 2014).

Importantly, cell-cycle re-entry (CCR) by post-mitotic neurons preludes much of the massive neuron death that occurs in $\mathrm{AD}$ (Arendt, 2012) and is also associated with impaired synaptic plasticity (Arendt and Brückner, 2007). A $\beta O$ treatment of primary neurons results in activation of the kinases CaMKII, PKA, and fyn, which induce ectopic CCR by a mechanism that relies on site-specific tau phosphorylation catalyzed by those kinases (Seward et al., 2013). Neuronal CCR is also present in hAPPJ20 AD model mice at 6 months, but absent in comparable tau KO littermates (Seward et al., 2013).

\section{NUCLEAR TAU}

Although, it is predominately expressed in the axon, tau can also be found in other cellular compartments, including the

\section{REFERENCES}

Ahmed, T., Van der Jeugd, A., Blum, D., Galas, M. C., D’hooge, R., and Buee, L. (2014). Neurobiology of Aging Cognition and hippocampal synaptic plasticity in mice with a homozygous tau deletion. Neurobiol. Aging 35, 2474-2478. doi: 10.1016/j.neurobiolaging.2014.05.005

Alonso, A. D., Di Clerico, J., Li, B., Corbo, C. P., Alaniz, M. E., GrundkeIqbal, I., et al. (2010). Phosphorylation of Tau at Thr212, Thr231, and Ser262 combined causes neurodegeneration. J. Biol. Chem. 285, 30851-30860. doi: 10.1074/jbc.M110.110957

Arendt, T. (2012). Cell cycle activation and aneuploid neurons in Alzheimer's disease. Mol. Neurobiol. 46, 125-135. doi: 10.1007/s12035-012-8262-0

Arendt, T., and Brückner, M. K. (2007). Linking cell-cycle dysfunction in Alzheimer's disease to a failure of synaptic plasticity. Biochim. Biophys. Acta 1772, 413-421. doi: 10.1016/j.bbadis.2006.12.005

Binder, L. I., Frankfurter, A., and Rebhun, L. I. (1985). The distribution of tau in the mammalian central nervous system. J. Cell Biol. 101, 1371-1378. doi: 10.1083/jcb.101.4.1371 nucleus, under normal physiological conditions. Its nuclear role is unresolved, but one theory proposes a protective role against DNA damage for nuclear tau, depending on its phosphorylation state (Sultan et al., 2011). Interestingly, tau was recently shown to induce chromatin relaxation, which subsequently leads to DNA damage and global changes in transcription (Frost et al., 2014).

\section{CONCLUSIONS}

The current understanding of tau identifies its hyperphosphorylation and subsequent mislocalization as seminal steps for $\mathrm{AD}$ pathogenesis. Once it becomes appropriately phosphorylated, tau loses its affinity for microtubules and becomes potently cytotoxic (Alonso et al., 2010). Over the course of $\mathrm{AD}$, hyper-phosphorylated tau ectopically enters the somadendritic compartment, where in conjunction with $\mathrm{A} \beta \mathrm{O}$, it promotes excitotoxicity at synapses. Additionally, tau phosphorylation modulates DNA integrity under cellular stress, and global changes in protein transcripts. Inhibiting aberrant tau phosphorylation may prove useful in the treatment of $\mathrm{AD}$. However, targeting tau phosphorylation will require a greater understanding on how site-specific tau phosphorylation alters its function.

\section{AUTHOR CONTRIBUTIONS}

SK wrote an advanced draft of this mini-review, which was then edited by GB.

\section{ACKNOWLEDGMENTS}

Recent work on $\mathrm{AD}$ in the Bloom lab has been supported by the Owens Family Foundation; the Alzheimer's Association; the Cure Alzheimer's Fund; NIH (1F31NS09244401A1); the University of Virginia's President's Fund for Excellence; Webb and Tate Wilson and the Fraternal Order of Eagles.

Bloom, G. S. (2014). Amyloid- $\beta$ and Tau. JAMA Neurol. 71, 505. doi: 10.1001/jamaneurol.2013.5847

Bolkan, B. J., and Kretzschmar, D. (2014). Loss of Tau results in defects in photoreceptor development and progressive neuronal degeneration in drosophila. Dev. Neurobiol. 1210-1225. doi: 10.1002/dneu. 22199

Braak, H., and Braak, E. (1991). Neuropathological stageing of Alzheimerrelated changes. Acta Neuropathol. 82, 239-259. doi: 10.1007/BF003 08809

Caceres, A., and Kosik, A. C. (1990). Inhibition of neurite polarity by tau antisense oligonucleotides in primary cerebellar neurons. Nature 343, 461-463. doi: $10.1038 / 343461 \mathrm{a} 0$

Chabrier, M. A., Blurton-jones, M., Agazaryan, A. A., Nerhus, J. L., Martinez-coria, H., and Laferla, F. M. (2012). Soluble A $\beta$ promotes wild-type tau pathology in vivo. J. Neurosci. 32, 17345-17350. doi: 10.1523/JNEUROSCI.017212.2012

Chabrier, M. A., Cheng, D., Castello, N. A., Green, K. N., and LaFerla, F. M. (2014). Synergistic effects of amyloid-beta and wild-type human tau on dendritic spine 
loss in a floxed double transgenic model of Alzheimer's disease. Neurobiol. Dis. 64, 107-117. doi: 10.1016/j.nbd.2014.01.007

Dawson, H. N., Ferreira, A., Eyster, M. V., Ghoshal, N., Binder, L. I., and Vitek, M. P. (2001). Inhibition of neuronal maturation in primary hippocampal neurons from tau deficient mice. J. Cell Sci. 114, 1179-1187.

Dixit, R., Ross, J. L., Goldman, Y. E., and Holzbaur, E. L. F. (2008). Differential regulation of dynein and inesin motor proteins by Tau. Science 319, 8-11. doi: $10.1126 /$ science. 1152993

Frandemiche, M. L., De Seranno, S., Rush, T., Borel, E., Elie, A., Arnal, I., et al. (2014). Activity-dependent tau protein translocation to excitatory synapse is disrupted by exposure to amyloid-beta oligomers. J. Neurosci. 34, 6084-6097. doi: 10.1523/JNEUROSCI.4261-13.2014

Frost, B., Hemberg, M., Lewis, J., and Feany, M. B. (2014). Tau promotes neurodegeneration through global chromatin relaxation. Nat. Neurosci. 17, 357-366. doi: 10.1038/nn.3639

Goedert, M., and Jakes, R. (1990). Expression of separate isoforms of human tau protein: correlation with the tau pattern in brain and effects on tubulin polymerization. EMBO J. 9, 4225-4230.

Goedert, M., Spillantini, M. G., Jakes, R., Rutherford, D., and Crowther, R. A. (1989a). Multiple isoforms of human microtubule-associated protein tau: sequences and localization in neurofibrillary tangles of Alzheimer's disease. Neuron 3, 519-526.

Goedert, M., Spillantini, M. G., Potier, M. C., Ulrich, J., and Crowther, R. A. (1989b). Cloning and sequencing of the cDNA encoding an isoform of microtubule-associated protein tau containing four tandem repeats: differential expression of tau protein mRNAs in human brain. EMBO J. 8, 393-399.

Götz, J., Chen, F., van Dorpe, J., and Nitsch, R. M. (2001). Formation of neurofibrillary tangles in P301l tau transgenic mice induced by Abeta 42 fibrils. Science 293, 1491-1495. doi: 10.1126/science.1062097

Götz, J., Probst, A., Spillantini, M. G., Schäfer, T., Jakes, R., Bürki, K., et al. (1995). Somatodendritic localization and hyperphosphorylation of tau protein in transgenic mice expressing the longest human brain tau isoform. EMBO J. $14,1304-1313$

Grundke-Iqbal, I., Iqbal, K., Tung, Y. C., Quinlan, M., Wisniewski, H. M., and Binder, L. I. (1986). Abnormal phosphorylation of the microtubule-associated protein tau (tau) in Alzheimer cytoskeletal pathology. Proc. Natl. Acad. Sci. U.S.A. 83, 4913-4917. doi: 10.1073/pnas.83.13.4913

Harada, A., Oguchi, K., Okabe, S., Kuno, J., Terada, S., Ohshima, T., et al. (1994). Altered microtubule organization in small-calibre axons of mice lacking tau protein. Nature 369, 488-491. doi: 10.1038/369488a0

Hardy, J. A., and Higgins, G. A. (1992). Disease : Alzheimer's cascade hypothesis amyloid. Sci. New Ser. 256, 184-185. doi: 10.1126/science.1566067

Himmler, A., Drechsel, D., Kirschner, M. W., and Martin, D. W. (1989). Tau consists of a set of proteins with repeated C-terminal microtubule-binding domains and variable N-terminal domains. Mol. Cell. Biol. 9, 1381-1388. doi: 10.1128/MCB.9.4.1381

Hong, M., Zhukareva, V., Vogelsberg-Ragaglia, V., Wszolek, Z., Reed, L., Miller, B. I., et al. (1998). Mutation-specific functional impairments in distinct tau isoforms of hereditary FTDP-17. Science 282, 1914-1917. doi: $10.1126 /$ science.282.5395.1914

Hoover, B. R., Reed, M. N., Su, J., Penrod, R. D., Kotilinek, L. A., Grant, M. K., et al. (2010). Tau mislocalization to dendritic spines mediates synaptic dysfunction independently of neurodegeneration. Neuron 68, 1067-1081. doi: 10.1016/j.neuron.2010.11.030

Ittner, L. M., Ke, Y. D., Delerue, F., Bi, M., Gladbach, A., van Eersel, J., et al. (2010). Dendritic function of Tau Mediates Amyloid- $\beta$ Toxicity in Alzheimer's disease mouse models. Cell 142, 387-397. doi: 10.1016/j.cell.2010. 06.036

Kimura, T., Whitcomb, D. J., Jo, J., Regan, P., Piers, T., Heo, S., et al. (2013). Microtubule-associated protein tau is essential for long-term depression in the hippocampus. Philos. Trans. R. Soc. Lond. B Biol. Sci. 369:20130144. doi: 10.1098/rstb.2013.0144

King, M. E., Kan, H.-M., Baas, P. W., Erisir, A., Glabe, C. G., and Bloom, G. S. (2006). Tau-dependent microtubule disassembly initiated by prefibrillar beta-amyloid. J. Cell Biol. 175, 541-546. doi: 10.1083/jcb.200605187

Kondo, J., Honda, T., Mori, H., Hamada, Y., Miura, R., Ogawara, M., et al. (1988). The carboxyl third of tau is tightly bound to paired helical filaments. Neuron 1, 827-834. doi: 10.1016/0896-6273(88)90130-4
Kosik, K. S., Orecchio, L. D., Bakalis, S., and Neve, R. L. (1989). Developmentally regulated expression of specific tau sequences. Neuron 2, 1389-1397. doi: 10.1016/0896-6273(89)90077-9

Kosik, K. S., Orecchio, L. D., Binder, L., Trojanowski, J. Q., Lee, V. M., and Lee, G. (1988). Epitopes that span the tau molecule are shared with paired helical filaments. Neuron 1, 817-825. doi: 10.1016/0896-6273(88)90129-8

Krstic, D., and Knuesel, I. (2012). Deciphering the mechanism underlying late-onset Alzheimer disease. Nat. Rev. Neurol. 9, 25-34. doi: 10.1038/nrneurol.2012.236

Larson, M., Sherman, M. A., Amar, F., Nuvolone, M., Schneider, J. A., Bennett, D. A., et al. (2012). The Complex PrP c -Fyn couples human oligomeric A $\beta$ with pathological Tau changes in Alzheimer's disease. J. Neurosci. 32, 16857-16871. doi: 10.1523/JNEUROSCI.1858-12.2012

Lei, P., Ayton, S., Finkelstein, D. I., Spoerri, L., Ciccotosto, G. D., Wright, D. K., et al. (2012). Tau deficiency induces parkinsonism with dementia by impairing APP-mediated iron export. Nat. Med. 18, 291-295. doi: 10.1038/nm.2613

Lei, P., Ayton, S., Moon, S., Zhang, Q., Volitakis, I., Finkelstein, D. I., et al. (2014). Motor and cognitive deficits in aged tau knockout mice in two background strains. Mol. Neurodegen. 9, 1-12. doi: 10.1186/1750-1326-9-29

Leroy, K., Ando, K., Laporte, V., Dedecker, R., Suain, V., Octave, J., et al. (2012). Lack of Tau proteins rescues neuronal cell death and decreases amyloidogenic processing of APP in APP / PS1 mice. AJPA 181, 1928-1940. doi: 10.1016/j.ajpath.2012.08.012

Lewis, J., Dickson, D. W., Lin, W. L., Chisholm, L., Corral, A., Jones, G., et al. (2001). Enhanced neurofibrillary degeneration in transgenic mice expressing mutant Tau and APP. Science 293, 1487-1491. doi: 10.1126/science.1058189

Li, S., Hong, S., Shepardson, N. E., Walsh, D. M., Shankar, G. M., and Selkoe, D. (2009). Soluble oligomers of amyloid $\beta$ Protein facilitate hippocampal longterm depression by disrupting neuronal glutamate uptake. Neuron 62, 788-801. doi: 10.1016/j.neuron.2009.05.012

Li, Z., Hall, A. M., Kelinske, M., and Roberson, E. D. (2014). Neurobiology of Aging Seizure resistance without parkinsonism in aged mice after tau reduction. Neurobiol. Aging 35, 2617-2624. doi: 10.1016/j.neurobiolaging.2014.05.001

Lopes, S., Lopes, A., Pinto, V., Guimar, M. R., Sardinha, V. M., Duarte-silva, S., et al. (2016). Absence of Tau triggers age-dependent sciatic nerve morphofunctional deficits and motor impairment. Aging Cell. doi: 10.1111/acel.12391. [Epub ahead of print].

Ma, Q., Zuo, X., Yang, F., Ubeda, O. J., Gant, D. J., Alaverdyan, M., et al. (2014). Loss of MAP function leads to hippocampal synapse loss and deficits in the morris water maze with aging. J. Neurosci. 34, 7124-7136. doi: 10.1523/JNEUROSCI.3439-13.2014

Mairet-Coello, G., Courchet, J., Pieraut, S., Courchet, V., Maximov, A., and Polleux, F. (2013). The CAMKK2-AMPK kinase pathway mediates the synaptotoxic effects of $A \beta$ oligomers through Tau phosphorylation. Neuron 78, 94-108. doi: 10.1016/j.neuron.2013.02.003

Miller, E. C., Teravskis, P. J., Dummer, B. W., Zhao, X., Huganir, R. L., and Liao, D. (2014). Tau phosphorylation and tau mislocalization mediate soluble $A \beta$ oligomer-induced AMPA glutamate receptor signaling deficits. Eur. J. Neurosci. 39, 1214-1224. doi: 10.1111/ejn.12507

Morris, M., Hamto, P., Adame, A., Devidze, N., Masliah, E., and Mucke, L. (2013). Neurobiology of Aging Age-appropriate cognition and subtle dopamineindependent motor de fi cits in aged Tau knockout mice. Neurobiol. Aging 34, 1523-1529. doi: 10.1016/j.neurobiolaging.2012.12.003

Nakamura, K., Zhen Zhou, X., and Ping Lu, K. (2012). Cis phosphorylated tau as the earliest detectable pathogenic conformation in Alzheimer disease, offering novel diagnostic and therapeutic strategies. Prion 7, 117-120. doi: $10.4161 /$ pri.22849

Nukina, N., and Ihara, Y. (1986). One of the antigenic determinants of paired helical filaments is related to tau protein. J. Biochem. 99, 1541-1544.

Nussbaum, J. M., Schilling, S., Cynis, H., Silva, A., Swanson, E., Wangsanut, T., et al. (2012). Prion-like behaviour and tau-dependent cytotoxicity of pyroglutamylated amyloid- $\beta$. Nature 485, 651-655. doi: 10.1038/nature 11060

Regan, P., Piers, X. T., Yi, J., Kim, D., Huh, S., Park, S. J., et al. (2015). Tau Phosphorylation at Serine 396 Residue Is Required for Hippocampal LTD. J. Neurosci. 35, 4804-4812. doi: 10.1523/JNEUROSCI.2842-14.2015

Rodríguez-Martín, T., Cuchillo-Ibáñez, I., Noble, W., Nyenya, F., Anderton, B. H., and Hanger, D. P. (2013). Tau phosphorylation affects its 
axonal transport and degradation. Neurobiol. Aging 34, 2146-2157. doi: 10.1016/j.neurobiolaging.2013.03.015

Sapir, T., Frotscher, M., Levy, T., Mandelkow, E., and Reiner, O. (2012). Tau's role in the developing brain: implications for intellectual disability. Hum. Mol. Gen. 21, 1681-1692. doi: 10.1093/hmg/ddr603

Seward, M. E., Swanson, E., Norambuena, A., Reimann, A., Cochran, J. N., Li, R., et al. (2013). Amyloid- $\beta$ signals through tau to drive ectopic neuronal cell cycle re-entry in Alzheimer's disease. J. Cell Sci. 126(Pt 5), 1278-1286. doi: 10.1242/ jcs. 1125880

Silva, D. F. F., Esteves, A. R., Arduino, D. M., Oliveira, C. R., and Cardoso, S. M. (2011). Amyloid- $\beta$-induced mitochondrial dysfunction impairs the autophagic lysosomal pathway in a tubulin dependent pathway. J. Alzheimers. Dis. 26, 565-581. doi: 10.3233/JAD-2011-110423

Sperling, R. A., LaViolette, P. S., O’Keefe, K., O'Brien, J., Rentz, D. M., Pihlajamaki, M., et al. (2009). Amyloid deposition is associated with impaired default network function in older persons without dementia. Neuron 63, 178-188. doi: 10.1016/j.neuron.2009.07.003

Stamer, K., Vogel, R., Thies, E., Mandelkow, E., and Mandelkow, E.-M. (2002). Tau blocks traffic of organelles, neurofilaments, and APP vesicles in neurons and enhances oxidative stress. J. Cell Biol. 156, 1051-1063. doi: $10.1083 /$ jcb. 200108057

Sultan, A., Nesslany, F., Violet, M., Bégard, S., Loyens, A., Talahari, S., et al. (2011). Nuclear tau, a key player in neuronal DNA protection. J. Biol. Chem. 286, 4566-4575. doi: 10.1074/jbc.M110.199976
Tucker, K. L., Meyer, M., and Barde, Y. A. (2001). Neurotrophins are required for nerve growth during development. Nat. Neurosci. 4, 29-37. doi: 10.1038/ 82868

Weingarten, M. D., Lockwood, A. H., Hwo, S. Y., and Kirschner, M. W. (1975). A protein factor essential for microtubule assembly. Proc. Natl. Acad. Sci. U.S.A. 72, 1858-1862. doi: 10.1073/pnas.72.5.1858

Witman, G. B., Cleveland, D. O. N. W., Weingarten, M. D., and Kirschner, M. W. (1976). Tubulin requires tau for growth onto microtubule initiating sites. Proc. Natl. Acad. Sci. U.S.A. 73, 4070-4074.

Wood, J. G., Mirra, S. S., Pollock, N. J., and Binder, L. I. (1986). Neurofibrillary tangles of Alzheimer disease share antigenic determinants with the axonal microtubule-associated protein tau (tau). Proc. Natl. Acad. Sci. U.S.A. 83, 4040-4043. doi: 10.1073/pnas.83.11.4040

Conflict of Interest Statement: The authors declare that the research was conducted in the absence of any commercial or financial relationships that could be construed as a potential conflict of interest.

Copyright (c) 2016 Khan and Bloom. This is an open-access article distributed under the terms of the Creative Commons Attribution License (CC BY). The use, distribution or reproduction in other forums is permitted, provided the original author(s) or licensor are credited and that the original publication in this journal is cited, in accordance with accepted academic practice. No use, distribution or reproduction is permitted which does not comply with these terms. 